\title{
Probiotic Use for the Prevention of Necrotizing Enterocolitis in Preterm Infants
}

\author{
Fatma Nur Sari and Ugur Dilmen
}

Additional information is available at the end of the chapter

http://dx.doi.org/10.5772/50049

\section{Introduction}

Necrotizing enterocolitis (NEC) is among the most common and devastating diseases that primarily afflicts preterm infants in neonatal intensive care units (NICU) (1). Despite recent advances in neonatal care, the incidence of necrotizing enterocolitis and the associated morbidity and mortality have remained unchanged because of the improved survival for smaller, more premature infants (2). Both medical and surgical management play critical role in the treatment of NEC once it occurs, but prevention is likely to have the most dramatic impact on overall morbidity and mortality.

\section{Epidemiology}

The incidence of NEC varies among NICUs worldwide, but ranges $3 \%$ and $28 \%$ with an average of $7 \%$ in infants born weighing less than $1500 \mathrm{~g}$ (3). NEC occurs more commonly in the smallest and most immature infants, with the incidence increasing inversely to gestational age and birth weight among appropriately grown preterm infants. Although NEC is almost exclusively a disease of prematurity, $5 \%$ to $10 \%$ of cases occur in infants born greater than or equal to 37 weeks gestation (4). Most of the infants in whom NEC develops are previously fed and the disease usually occurs in the second week of life after the initiation of enteral feeding (5).

The estimated rate of death related with NEC ranges between 20 and $30 \%$, with the highest rate among infants requiring surgery (6). Beyond the mortality and gastrointestinal morbidities, NEC is also the harbinger of neurologic deficits and developmental delay (7). 


\section{Pathophysiology}

NEC is a disease with a multifactorial etiology leading to the one common final pathway of necrosis and inflammation of the neonatal intestine (8). Although the pathophysiology of NEC is incompletely understood, epidemiologic studies have identified multiple factors that increase an infant's risk for the development of NEC, although prematurity, enteral feeding, intestinal ischemia/asphyxia and bacterial colonization are thought to play central roles in disease pathogenesis (9).

Prematurity is the most consistent and important risk factor for NEC. Anand et al. (10) proposed major altered components of the intestinal barrier of preterm neonates such as disruption of the integrity of epithelial tight junctions, impaired peristalsis and deficiencies in components of the mucous coat that may contribute to the onset of NEC (11-13).

Enteral feeding is a significant risk factor for disease in preterm infants, because most cases of NEC occur after feedings have been introduced. Although the precise relationship between enteral feeding and NEC remain poorly understood, studies have identified the importance of breast milk as opposed to formula, osmolality, volume and rate of feeding as important factors $(14,15)$. Breast milk appears to reduce the incidence of NEC in human studies and controlled animal models $(16,17)$.

Intestinal ischemia is another risk factor in the development of NEC. There is a delicate balance between vasodilatation and vasoconstriction in neonatal circulation, mediated formerly by nitric oxide and the latter by endothelin- 1 . The basal intestinal vascular resistance is decreased by the predominance of nitric oxide. Pathologic states cause endothelial dysfunction which leads to endothelin-1 activation and resultant vasoconstriction, intestinal ischemia, and cellular injury (18).

GI tract of the preterm infants are susceptible to abnormal bacterial colonization because of the immature immunologic defenses (9). The intestinal flora that is normally populated plays an important role in maintaining the intestinal barrier, and also has the ability to dampen the inflammatory response. Colonization of the intestine with pathogenic microorganisms, depending on the exposition to a variety of nosocomial bacteria in the NICUs and immature immune systems, may serve as predisposing factors in development of NEC in preterm infants (19).

\section{Diagnosis and management}

The clinical syndrome associated with NEC is nonspecific. Infants with NEC may exhibit several gastrointestinal signs including abdominal distention, increased gastric residuals, occult or gross blood in the stool, and abdominal wall erythema or ecchymosis. In addition to GI-specific signs, NEC infants may exhibit systemic signs such as lethargy, apnea, bradycardia and temperature instability (19).

The diagnosis of disease continues to be made with the use of pathognomonic radiographic findings. The most specific signs, which still are the only "signs" that allow 
the diagnosis to be confirmed prior to surgical inspection of the intestine, are pneumatosis intestinalis in most cases, hepatic portal venous gas or pneumoperitoneum in a minority of cases. A diagnosis requires one of the specific radiographic findings or direct inspection of the intestine in the clinical context $(5,20)$. As soon as the diagnosis of NEC is suspected, initial management should include bowel rest, decompression, cultures of blood, urine and sputum, administration of broad-spectrum antibiotics, appropriate fluid resuscitation, serial abdominal examinations and radiographs. Surgical intervention for NEC is required in $30 \%$ to $50 \%$ of cases reported; therefore close observation with serial examinations and radiographs is essential. Surgical intervention involving primer peritoneal drainage or laparatomy with the resection of affected bowel are generally required in infants with intestinal perforation or deteriorating clinical condition (20).

\section{Preventative strategies for NEC}

Based on the epidemiologic studies and understanding of the pathophysiology there have been several approaches attempted to prevent NEC in animal and human studies. Reduction of NEC has been shown with breast milk feeding, antibiotic prophylaxis, steroids, IgA supplementation, probiotics, epidermal growth factor, polyunsaturated fatty acids, platelet activating factor (PAF) antagonists, PAF-acetylhydrolase, trefoil factor, leukocyte depletion, and oxygen radical scavengers in animal models. In human studies, there remains no standard effective alternative for NEC prevention, although breast milk feeding is the best option that neonatologists have to offer. Besides breast milk feeding, strategies with the most evidence supporting their effectiveness are careful feeding advancement and prophylactic probiotics supplementation in at-risk neonates $(4,5)$.

\section{Probiotic prophylaxis in NEC}

The intestine of the newborn is devoid of bacterial flora at birth but is rapidly colonized thereafter (9). Although the maternal flora constitutes the main source of intestinal colonization, gestational age, the mode of delivery, the neonatal diet and genetic factors also influence the colonization (21).

Colonization by commensal bacteria is required for the normal development and maturation of the newborn intestine. Lactobacilli and Bifidobacteria that are the principal kinds of probiotics bacteria predominate in the normal gut flora of healthy, breastfed, term neonates (22). In contrast, the intestine of the preterm infant tends to be colonized by different microorganisms, predominantly coliforms, enterococci and bacteroides species (23). Even among VLBW infants receiving breast milk, Sakata et al. (24) found that the Bifidobacteria were undetectable in the intestinal flora during the first 1 to 2 weeks after birth and did not predominate until after the third week of life. Hoy et al. (25) and Millar et al. (26) observed a decline in the variety of species and shift to a predominance of Enterobacteriaceae before the onset of NEC. 
Intestinal microbiological flora is an important factor in the host-defense mechanism against bacterial infections. The combination of an increase in potentially pathogenic microorganisms together with a decrease "in normal flora" found in preterm infants is one of the factors that render these infants at increased risk of developing NEC $(23,27)$. It has been suggested that the growth of pathogens might be prevented by inducing the colonization of the intestine non-pathogenic bacteria (probiotics) of species normally resident in the gut of preterm and term infants (28).

The identification of probiotics bacterial species involved in gut homeostasis and potential therapeutic benefits of probiotics have led to interest in their use in the prevention of NEC $(29,30)$. Probiotics compete with other microbes for binding sites and substrates in the bowel, enhance the IgA mucosal response, improve the mucosal barrier, reduce mucosal permeability, stimulate intestinal mucosal lactase activity, increase anti-inflammatory cytokines, and produce a wide range of antimicrobial substances such as bacteriocins, microcins, reuterin, hydrogen peroxide and hydrogen ions $(20,28)$.

Gastrointestinal mucosa is the primary interface between the external environment and the immune system. Whenever intestinal microflora reduces, antigen transport is increased indicating that the normal gut microflora maintains gut defenses (31). The non-pathogenic probiotic bacteria interact with the gut epithelial cells and the immune cells to start the immune signals. These bacteria must interact with $\mathrm{M}$ cells in the Peyer's patches, with gut epithelial cells, and with associated immune cells. Probiotic bacteria have been shown to modulate immunoglobulin production. Secretory IgA plays an important role in mucosal immunity, contributing to the barrier against pathogenic bacteria and viruses. The increase in the number of IgA producing cells was the most remarkable property induced by probiotic organisms $(32,33)$.

Probiotic supplementation has resulted in a reduction in the incidence of NEC-like intestinal lesions in several animal models. Caplan et al. (34) demonstrated that Bifidobacteria supplementation resulted in intestinal colonization and subsequent reduction in NEC-like lesions in a neonatal rat model of intestinal ischemia/reperfusion. Butel et al. (35) showed in a NEC model in quail, that supplementation with Bifidobacteria prevented the development of cecal lesions reminiscent of NEC.

Several studies have specially assessed the colonization pattern and the incidence of NEC in preterm infants supplemented with various probiotics $(19,36-38)$. (Table 1)

A randomized controlled trial found that infants whose feed was supplemented with Bifidobacterium breve had higher rates of fecal bifidobacterial colonization at 2 weeks of age (73 vs. $12 \%$ ), improved weight gain and had feeding tolerance. However, the incidence and severity of NEC were not reported in this study (39).

In a multicenter double-blind study, preterm infants with a gestational age of $<33$ weeks or birth weight of $<1500 \mathrm{~g}$, who survived 42 weeks, were randomized to receive either placebo or L. rhamnosus GG (LB-GG) once a day, starting with the first fed until discharged. The incidence of urinary tract infection, bacterial sepsis and NEC were examined as outcome 
measures. There were no significant differences between the probiotics and placebo groups with regard to any of the outcome variables (28).

Another study performed by Bin-Nun et al. (40) was conducted to test the hypothesis that normalizing the intestinal flora by administration of prophylactic probiotics would provide a natural defense, thereby reducing both the incidence and severity of NEC in preterm infants. Preterm infants $\leq 1500 \mathrm{~g}$ birth weight were randomized to either receive a daily feeding supplementation with a probiotic mixture (Bifidobacteria infantis, Bifidobacteria bifidus, and Streptococcus thermophilus) of $10^{9} \mathrm{cfu}$ /day or to not receive feed supplements. In this study, probiotic supplementation had resulted in a reduction in the incidence and the severity of NEC in very low birth weight (VLBW) infants.

In addition, Lin et al. (19) reported a decrease in NEC, NEC plus mortality and severity of NEC, following probiotics L. acidophilus and B. infantis (Infloran), prophylaxis in a prospective, randomized blinded study. They also recently reported a multicenter-blinded trial regarding who were randomized to receive Bifidobacterium bifidum and L. acidophilus for 6 weeks. The results showed a significant reduction in the incidence of death or NEC and no adverse effect, such as sepsis, flatulence or diarrhea (37).

Similarly, Hoyos (36) reported a significant reduction in the incidence of NEC and NECassociated death in infants in the NICU after the prophylactic administration of probiotics in the form of Infloran-supplemented enteral feeding. However, infants were more mature and generally had higher birth weights; it is not a blinded trial and comparison was made with historical controls.

The results of the study performed by Sari et al (38) suggested a trend toward lower incidence of NEC and, death or NEC, although the difference was not statistically significant. None of the L. sporogenes-supplemented fed infants died from NEC; they could not find significant difference in severity of NEC or in mortality rate attributable to NEC between the probiotics and control groups. The use of a single probiotics agent rather than two agents and utility of a relatively low dose of L. sporogenes may explain, at least in part, the smaller treatment effect in their study. Longer duration of umbilical venous catheterization in probiotics group also may be another cause in the lesser effect of L. sporogenes on NEC prevention.

In a recent report by Manzoni et al. (41) routinely supplementation of probiotic LB-GG in a large, 6-year VLBW infants cohort was proved microbiologically safe and clinically well tolerated.

Although some of the studies (19) predicated that probiotics may reduce the incidence of sepsis; literature did not confirm this association $(42,43)$. Sari et al. (38) also did not show that L. sporogenes reduced the incidence of sepsis in VLBW infants. Sepsis has a complex pathogenesis that is favored by many factors (that is, immune deficiencies of preterm infants, type and frequency of invasive procedures and so on) that cannot be influenced by probiotic administration. The main effect of orally administered probiotics is in the 
gastrointestinal tract, and so probiotics alone cannot overcome the invasive procedures including infection.

Lactobacilli and Bifidobacteria are generally regarded as non-pathogenic, except a few reported cases of Lactobacillus bacteremia that seemed to occur in immunocompromised or extremely sick infants receiving high doses of Lactobacillus (44). Kunz et al. (45) described L. bacteremia in two preterm infants who received LB- GG, and both of those infants had short-gut syndrome. The other authors did not observe sepsis attributable to probiotics in the studies $(28,44,45)$. Sari et al (38) observed no cases of sepsis or other adverse effects, such as diarrhea, flatulence attributable to probiotic supplementation.

In 2011, Alfaleh et al. (29) performed a meta-analysis of randomized controlled trials, including some of those discussed here, to evaluate the efficacy of probiotics in the prevention of severe NEC and/or sepsis in preterm infants. Sixteen eligible trials randomizing 2842 infants were included. Included trials were highly variable with regard to enrollment criteria (i.e. birth weight and gestational age), baseline risk of NEC in the control groups, timing, dose, formulation of the probiotics, and feeding regimens. In a metaanalysis of trial data, enteral probiotics supplementation significantly reduced the incidence of severe NEC (stage $\geq 2$ ) (typical RR $0.35,95 \%$ CI 0.24 to 0.52 ) and mortality (typical RR 0.40, $95 \%$ CI 0.27 to 0.60 ). There was no evidence of significant reduction of nosocomial sepsis (typical RR 0.90, 95\% CI 0.76 to 1.07). The included trials reported no systematic infection with probiotic supplemental organism. Author concluded that enteral supplementation of probiotics prevents severe NEC and all cause mortality in preterm infants.

A recent systematic review performed by Mihatsch et al. (46) reported that there is insufficient evidence to recommend routine probiotics. However there is encouraging data which justifies the further investigation regarding the efficacy and safety of specific probiotics in circumstances of high local incidence of severe NEC.

There is limited information about the long-term effects of probiotics supplementation in neonates. Chou et al. (47) reported the long-term neurodevelopmental outcomes of preterm infants in their trial of oral probiotics for NEC. A total of $83.1 \%$ of infants from their trial were assessed by Bayley infant developmental assessment tool (BSID-II) at 3 years' corrected age; 1 of 153 and 4 of 148 had died after discharge. There were no significant differences in growth, neurodevelopmental and sensory outcomes at 3 years' corrected age. Recently, a prospective follow-up study was conducted to evaluate growth and neurodevelopmental outcomes in a cohort of infants enrolled in a randomized controlled trial of oral probiotics for the prevention of NEC in VLBW infants. The authors concluded that administration of oral probiotics to VLBW infants in the early neonatal period had no adverse effects on growth, neuromotor, neurosensory, and cognitive outcomes at 18-22 months' corrected age (48). Given the importance of this issue, it is critical that authors of all trials in this field report long-term neurodevelopmental outcomes of the enrolled infants. 


\begin{tabular}{|c|c|c|c|c|c|}
\hline Source & GA/BW & $\begin{array}{l}\text { Probiotic } \\
\text { Agent(s) }\end{array}$ & $\begin{array}{l}\text { Dosage and } \\
\text { Duration }\end{array}$ & $\begin{array}{l}\text { Type of } \\
\text { milk }\end{array}$ & Results \\
\hline $\begin{array}{l}\text { Hoyos et al, } \\
\text { (36) } 1999\end{array}$ & $<37$ wk & LB-A,BI & $\begin{array}{l}\text { LB-A } 0.25 \times 10^{9} \mathrm{CFU} \text {, } \\
\text { BI } 0.25 \times 10^{9} \mathrm{CFU} \text {, once } \\
\text { daily from first feed } \\
\text { until discharge }\end{array}$ & $\begin{array}{l}\text { MM, DM, } \\
\text { or FM }\end{array}$ & $\begin{array}{l}\text { Significant } \\
\text { decrease in NEC } \\
\text { and NEC } \\
\text { associated } \\
\text { mortality }\end{array}$ \\
\hline $\begin{array}{l}\text { Dani et al, } \\
\text { (28) } 2002\end{array}$ & $\begin{array}{l}<33 \text { wk or } \\
<1500 \mathrm{~g}\end{array}$ & LB-GG & $\begin{array}{l}6 \times 10^{9} \mathrm{CFU} \text { once daily } \\
\text { from first feed until } \\
\text { discharge }\end{array}$ & $\begin{array}{l}\text { MM, DM, } \\
\text { or FM }\end{array}$ & $\begin{array}{l}\text { Non-significant } \\
\text { decrease in NEC, } \\
\text { UTI and sepsis }\end{array}$ \\
\hline $\begin{array}{l}\text { Bin-Nun et al, } \\
\text { (40) } 2005\end{array}$ & $<1500 \mathrm{~g}$ & BI, ST, BBB & $\begin{array}{l}\text { BI } 0.35 \times 10^{9} \mathrm{CFU}, \mathrm{ST} \\
0.35 \times 10^{9} \mathrm{CFU}, \mathrm{BBB} \\
0.35 \times 10^{9} \mathrm{CFU} \text { once } \\
\text { daily from first feed } \\
\text { to } 36 \mathrm{wk} \text { corrected } \\
\text { age }\end{array}$ & $\begin{array}{l}\text { MM or } \\
\text { FM }\end{array}$ & $\begin{array}{l}\text { Significant } \\
\text { decrease in NEC }\end{array}$ \\
\hline $\begin{array}{l}\text { Lin et al, } \\
\text { (19) } 2005\end{array}$ & $<1500 \mathrm{~g}$ & LB-A, BI & $\begin{array}{l}\text { LB-A } 1004356 \text { and BI } \\
1015697 \text { organisms } \\
\text { twice daily from day } \\
7 \text { until discharge }\end{array}$ & $\begin{array}{l}\text { MM or } \\
\text { DM }\end{array}$ & $\begin{array}{l}\text { Significant } \\
\text { decrease in NEC } \\
\text { or death }\end{array}$ \\
\hline $\begin{array}{l}\text { Lee et al, } \\
\text { (49) } 2007\end{array}$ & $<37$ wk & LB-A & $\begin{array}{l}10^{8} \mathrm{CFU} \text { from first } \\
\text { feed for } 14 \mathrm{~d}\end{array}$ & $\begin{array}{l}\text { MM or } \\
\text { FM }\end{array}$ & $\begin{array}{l}\text { Non-significant } \\
\text { decrease in NEC, } \\
\text { improved } \\
\text { feeding } \\
\text { tolerance }\end{array}$ \\
\hline $\begin{array}{l}\text { Lin et al, } \\
\text { (37) } 2008\end{array}$ & $\begin{array}{l}<34 \mathrm{wk} \text { and } \\
<1500 \mathrm{~g}\end{array}$ & LB-A, BBB & $\begin{array}{l}2 \times 10^{9} \mathrm{CFU} / \mathrm{d} \text { for } 6 \\
\mathrm{wk}\end{array}$ & $\begin{array}{l}\text { MM or } \\
\text { FM }\end{array}$ & $\begin{array}{l}\text { Significant } \\
\text { decrease in NEC } \\
\text { or death }\end{array}$ \\
\hline $\begin{array}{l}\text { Samanta et al } \\
(50), 2009\end{array}$ & $\begin{array}{l}<34 \text { wk and } \\
<1500 \mathrm{~g}\end{array}$ & $\begin{array}{l}\text { BBB, BB-L, } \\
\text { BI, LB-A }\end{array}$ & $\begin{array}{l}2.5 \times 10^{9} \mathrm{CFU} / \mathrm{d} \text { until } \\
\text { discharge }\end{array}$ & $\begin{array}{l}\text { MM or } \\
\text { FM }\end{array}$ & $\begin{array}{l}\text { Significant } \\
\text { decrease in NEC, } \\
\text { death or sepsis }\end{array}$ \\
\hline $\begin{array}{l}\text { Sari et al } \\
(38), 2011\end{array}$ & $\begin{array}{l}<33 \text { wk or } \\
<1500 \mathrm{~g}\end{array}$ & LB-S & $\begin{array}{l}0.35 \times 10^{9} \mathrm{CFU} / \mathrm{d} \text { from } \\
\text { first feed until } \\
\text { discharge }\end{array}$ & $\begin{array}{l}\text { MM or } \\
\text { FM }\end{array}$ & $\begin{array}{l}\text { Non-significant } \\
\text { decrease in NEC } \\
\text { or death, } \\
\text { improved } \\
\text { feeding } \\
\text { tolerance }\end{array}$ \\
\hline
\end{tabular}

Table 1. Studies examining effect of probiotic supplementation on incidence of NEC 
GA indicates gestational age; BW, birth weight; LB-A, Lactobacillus acidophilus; BI,Bifidobacteria infantis; LB-GG, Lactobacillus GG; ST, Streptococcus thermophilus; BBB, Bifidobacterium bifidus; BB-L, Bifidobacteria longum; LB-S, Lactobacillus sporogenes; CFU, colony forming unit; MM, mother's milk; DM, donor milk; FM, formula milk; UTI, urinary tract infection

\section{Summary}

NEC is one of the commonest causes of acute morbidity and mortality in preterm infants as well as a cause of long term disability for older children. The pathogenesis is multifactorial but probably requires the classic triad of injury to the intestinal mucosa, presence of enteral food substrate and the presence of bacteria and bacterial products. Recent advances in neonatology have led to improved survival for younger and smaller infants, and a resultant increase in the disease burden of NEC. The morbidity and mortality rates for NEC have still remained constant, by contrast with the improvement in outcomes for many prematurityrelated diseases. There are several prosperous researches that could ultimately result in novel preventative or therapeutic options but there is currently no effective preventive strategy, and treatment options are limited.

Although probiotics may be a promising approach for prevention and decreased severity of NEC, issues exist regarding the standardization of an appropriate probiotic supplement for neonates. Most studies have utilized various combinations of probiotic bacteria and amounts of culture-forming units for different lengths of time. These differences in methodology have created difficulties in elucidating the most beneficial probiotic supplement for the preterm population. Questions remain concerning the strains or combinations of strains that offer the best benefit. Potential exists for a significant difference in the magnitude of the benefit when administered to formula versus breast-fed neonates. There are also uncertainties over the optimal time to start probiotics in order to confer maximal benefit, possible adverse effects including probiotic-associated sepsis and tolerance of milk feeding and the long-term consequences of probiotic supplementation. So, before routine probiotic prophylaxis could be recommended to neonatologists, it would be important to have evidence in support of such use from large, prospective, single-protocol, randomized, double-blind trials.

\section{Author details}

Fatma Nur Sari* and Ugur Dilmen

Neonatal Intensive Care Unit in Zekai Tahir Burak Maternity and Teaching Hospital, Ankara, Turkey

${ }^{*}$ Corresponding Author 


\section{References}

[1] Neu J, Walker WA. Necrotizing enterocolitis. N Engl J Med 2011;364:255-64.

[2] Henry MC, Moss RL. Neonatal necrotizing enterocolitis. Semin Pediatr Surg 2008;17:98109.

[3] Uauy RD, Fanaroff AA, Korones SB, et al. Necrotizing enterocolitis in very low birth weight infants: biodemographic and clinical correlates. National Institute of Child Health and Human Development Neonatal Research Network. J Pediatr 1991;119:630-8.

[4] Caplan MS. Neonatal Necrotizing Enterocolitis: Clinical Observations, Pathophysiology, and Prevention. In: Martin RJ, Fanaroff AA, Walsh MC, editors. Fanaroff and Martin's Neonatal-Perinatal Medicine: Diseases of the Fetus and Infant. 9th Ed. ed. St. Louis, Missouri: Mosby; 2011. p. 1431-1442.

[5] Berman L, Moss RL. Necrotizing enterocolitis: an update. Semin Fetal Neonatal Med 2011;16:145-50.

[6] Fitzgibbons SC, Ching Y, Yu D, et al. Mortality of necrotizing enterocolitis expressed by birth weight categories. J Pediatr Surg 2009;44:1072-5; discussion 1075-6.

[7] Bedrick AD. Necrotizing enterocolitis: neurodevelopmental "risky business". J Perinatol 2004;24:531-3.

[8] Neu J. Necrotizing enterocolitis: the search for a unifying pathogenic theory leading to prevention. Pediatr Clin North Am 1996;43:409-32.

[9] Hunter CJ, Upperman JS, Ford HR, et al. Understanding the susceptibility of the preterm infant to necrotizing enterocolitis (NEC). Pediatr Res 2008;63:117-23.

[10] Anand RJ, Leaphart CL, Mollen KP, et al. The role of the intestinal barrier in the pathogenesis of necrotizing enterocolitis. Shock 2007;27:124-33.

[11] Allen A, Bell A, Mantle M, et al. The structure and physiology of gastrointestinal mucus. Adv Exp Med Biol 1982;144:115-33.

[12] Muresan Z, Paul DL, Goodenough DA. Occludin 1B, a variant of the tight junction protein occludin. Mol Biol Cell 2000;11:627-34.

[13] Cetin S, Ford HR, Sysko LR, et al. Endotoxin inhibits intestinal epithelial restitution through activation of Rho-GTPase and increased focal adhesions. J Biol Chem 2004;279:24592-600.

[14] Di Lorenzo M, Bass J, Krantis A. An intraluminal model of necrotizing enterocolitis in the developing neonatal piglet. J Pediatr Surg 1995;30:1138-42.

[15] Kamitsuka MD, Horton MK, Williams MA. The incidence of necrotizing enterocolitis after introducing standardized feeding schedules for infants between 1250 and 2500 grams and less than 35 weeks of gestation. Pediatrics 2000;105:37984.

[16] Caplan MS, Hedlund E, Adler L, et al. Role of asphyxia and feeding in a neonatal rat model of necrotizing enterocolitis. Pediatr Pathol 1994;14:1017-28. 
[17] Lucas A, Cole TJ. Breast milk and neonatal necrotising enterocolitis. Lancet 1990;336:1519-23.

[18] Nowicki PT. Ischemia and necrotizing enterocolitis: where, when, and how. Semin Pediatr Surg 2005;14:152-8.

[19] Lin HC, Su BH, Chen AC, et al. Oral probiotics reduce the incidence and severity of necrotizing enterocolitis in very low birth weight infants. Pediatrics 2005; 115:1-4.

[20] Thompson AM, Bizzarro MJ. Necrotizing enterocolitis in newborns: pathogenesis, prevention and management. Drugs 2008;68:1227-38.

[21] Ruemmele FM, Bier D, Marteau P, et al. Clinical evidence for immunomodulatory effects of probiotic bacteria. J Pediatr Gastroenterol Nutr 2009;48:126-41.

[22] Orrhage K, Nord CE. Factors controlling the bacterial colonization of the intestine in breastfed infants. Acta Paediatr Suppl 1999;88:47-57.

[23] Claud EC, Walker WA. Hypothesis: inappropriate colonization of the preterm intestine can cause neonatal necrotizing enterocolitis. FASEB J 2001;15:1398-403.

[24] Sakata H, Yoshioka H, Fujita K. Development of the intestinal flora in very low birth weight infants compared to normal full-term newborns. Eur J Pediatr 1985;144:18690.

[25] Hoy C, Millar MR, MacKay P, et al. Quantitative changes in faecal microflora preceding necrotising enterocolitis in preterm neonates. Arch Dis Child 1990;65:1057-9.

[26] Millar MR, MacKay P, Levene M, et al. Enterobacteriaceae and neonatal necrotising enterocolitis. Arch Dis Child 1992;67:53-6.

[27] Hall MA, Cole CB, Smith SL, et al. Factors influencing the presence of faecal lactobacilli in early infancy. Arch Dis Child 1990;65:185-8.

[28] Dani C, Biadaioli R, Bertini G, et al. Probiotics feeding in prevention of urinary tract infection, bacterial sepsis and necrotizing enterocolitis in preterm infants. A prospective double-blind study. Biol Neonate 2002;82:103-8.

[29] Alfaleh K, Anabrees J, Bassler D, et al. Probiotics for prevention of necrotizing enterocolitis in preterm infants. Cochrane Database Syst Rev 2011:CD005496.

[30] Embleton ND, Yates R. Probiotics and other preventative strategies for necrotising enterocolitis. Semin Fetal Neonatal Med 2008;13:35-43.

[31] Madsen K, Cornish A, Soper P, et al. Probiotic bacteria enhance murine and human intestinal epithelial barrier function. Gastroenterology 2001;121:580-91.

[32] Isolauri E, Kaila M, Mykkanen H, et al. Oral bacteriotherapy for viral gastroenteritis. Dig Dis Sci 1994;39:2595-600.

[33] Szajewska H, Kotowska M, Mrukowicz JZ, et al. Efficacy of Lactobacillus GG in prevention of nosocomial diarrhea in infants. J Pediatr 2001;138:361-5.

[34] Caplan MS, Miller-Catchpole R, Kaup S, et al. Bifidobacterial supplementation reduces the incidence of necrotizing enterocolitis in a neonatal rat model. Gastroenterology 1999;117:577-83. 
[35] Butel MJ, Waligora-Dupriet AJ, Szylit O. Oligofructose and experimental model of neonatal necrotising enterocolitis. Br J Nutr 2002;87 Suppl 2:S213-9.

[36] Hoyos AB. Reduced incidence of necrotizing enterocolitis associated with enteral administration of Lactobacillus acidophilus and Bifidobacterium infantis to neonates in an intensive care unit. Int J Infect Dis 1999;3:197-202.

[37] Lin HC, Hsu CH, Chen HL, et al. Oral probiotics prevent necrotizing enterocolitis in very low birth weight preterm infants: a multicenter, randomized, controlled trial. Pediatrics 2008;122:693-700.

[38] Sari FN, Dizdar EA, Oguz S, et al. Oral probiotics: Lactobacillus sporogenes for prevention of necrotizing enterocolitis in very low-birth weight infants: a randomized, controlled trial. Eur J Clin Nutr 2011;65:434-9.

[39] Kitajima H, Sumida Y, Tanaka R, et al. Early administration of Bifidobacterium breve to preterm infants: randomised controlled trial. Arch Dis Child Fetal Neonatal Ed 1997;76:F101-7.

[40] Bin-Nun A, Bromiker R, Wilschanski M, et al. Oral probiotics prevent necrotizing enterocolitis in very low birth weight neonates. J Pediatr 2005;147:192-6.

[41] Manzoni P, Lista G, Gallo E, et al. Routine Lactobacillus rhamnosus GG administration in VLBW infants: a retrospective, 6-year cohort study. Early Hum Dev 2011;87 Suppl 1:S35-8.

[42] Schanler RJ. Probiotics and necrotising enterocolitis in preterm infants. Arch Dis Child Fetal Neonatal Ed 2006;91:F395-7.

[43] Deshpande G, Rao S, Patole S, et al. Updated meta-analysis of probiotics for preventing necrotizing enterocolitis in preterm neonates. Pediatrics 2010;125:921-30.

[44] Land MH, Rouster-Stevens K, Woods CR, et al. Lactobacillus sepsis associated with probiotic therapy. Pediatrics 2005;115:178-81.

[45] Kunz AN, Noel JM, Fairchok MP. Two cases of Lactobacillus bacteremia during probiotic treatment of short gut syndrome. J Pediatr Gastroenterol Nutr 2004;38:457-8.

[46] Mihatsch WA, Braegger CP, Decsi T, et al. Critical systematic review of the level of evidence for routine use of probiotics for reduction of mortality and prevention of necrotizing enterocolitis and sepsis in preterm infants. Clin Nutr 2012;31:6-15.

[47] Chou IC, Kuo HT, Chang JS, et al. Lack of effects of oral probiotics on growth and neurodevelopmental outcomes in preterm very low birth weight infants. J Pediatr 2010;156:393-6.

[48] Sari FN, Eras Z, Dizdar EA, et al. Do Oral Probiotics Affect Growth and Neurodevelopmental Outcomes in Very Low-Birth-Weight Preterm Infants? Am J Perinatol 2012.

[49] Lee SJ, Cho SJ, Park EA. Effects of probiotics on enteric flora and feeding tolerance in preterm infants. Neonatology 2007;91:174-9. 
[50] Samanta M, Sarkar M, Ghosh P, et al. Prophylactic probiotics for prevention of necrotizing enterocolitis in very low birth weight newborns. J Trop Pediatr 2009;55:12831. 